\section{Ancient Greece and Modern Civilisation}

Is his Friday evening discourse delivered at the Royal Institution on January 25, Sir Richard Livingstone discussed the relation of modern civilisation to ancient Greece. Starting in a world where men believed that Zeus made thunder and that the sun and moon were gods, the Greeks originated science. Their actual scientific and philosophic achievement was remarkable (witness Aristarchus's discovery of the heliocentric system, the anticipation of modern thought in Anaximander's notion that men originate from animals of a different species, and Democritus's atomic thory). But even more remarkable is the grasp on the ideal of science shown in such sayings as: "Thought is the supreme excellence of men and wisdom consists in saying what is true and acting according to Nature, listening to her" (Heraclitus), and "It is a sin that Reason should be the subject or servant of anyone; its place is to be ruler of all" (Plato). Further, they grasped the idea of a civilisation based on the development of the useful arts. This appears in the myth of Prometheus as expounded by Aeschylus, in the "Antigone" and in many other passages in Greek literature. In this sense the Greeks were the creators of the characteristic spirit of modern civilisation. They grasped the ideal of science as completely as any of their successors. We have carried scientific discovery and technology to heights of which they never dreamed. But they formed a clearer and perhaps higher conception than we of the life which men should lead against the background of material civilisation. They can correct our eivilisation not only by the example of an existence, of which Goethe said that of all men the Greeks had dreamed the dream of life best, but also by reminding us that life is essentially a human problem and that ethics and political science are as fascinating as, and even more important than, physical science.

\section{Radio Research}

A DISCOVERY of great theoretical and practical significance in radio transmission was made last year. Listeners to foreign stations have, for some time past, noted that their reception was sometimes marred by a faint background of sound apparently made by a high-power long-wave station. At first, lack of selectivity in the receiver and possibly cross modulation were suspected. According to Prof. E. V. Appleton, in a paper in the Electrician of January 25, the interference is due to a cross modulation effect in one of the ionised layers in the atmosphere. The effect was first noticed in connexion with the powerful Luxembourg station, so it is generally called the Luxembourg effect. Recently amateurs belonging to the Radio Research League have shown that the phenomenon is also produced by the high-power stations at Droitwich and Athlone. Apparently a long-wave station of this type can impress the waves it produces on the ionised layer in its vicinity. If waves of another wave-length are reflected there, they acquire the modulation in question during the process of reflection. The present tendency of increasing the power of long-wave senders makes this phenomenon of practical importance. It brings about a type of interference over which the radio engineer has no control. Prof. Appleton comments also on the propagation of ultra-short waves (less than 8 metres). They are of importance because of their possible use in television. Apparently there is no acceptable evidence that 'round the world' communication will ever be possible with such short wavelengths. The lowest possible wave-length appears to be determined by the finite value of the electrification in the upper atmosphere.

\section{International Comparison of Radio Frequency Standards}

The technique of modern radio communication demands a very high degree of precision in the control and measurement of frequency. Considerable attention is therefore devoted by the more important national administrations to the development and maintenance of accurate frequency standards. In Great Britain one of the standards installed at the National Physical Laboratory provides a frequency of 1,000 eycles per second, the stability of which is better than one part in ten million. In order that this standard may be compared with those of other countries, the derived alternating current is used to modulate the carrier wave of a radio transmitting station. At the distant receiving station the modulation is extracted from the arriving signal and its frequency is compared with that of the local standard. In this manner frequency comparison measurements may be carried out simultaneously in differentcountries. Under the auspiees of the Union Radio Scientifique Internationale, and with the co-operation of the British Broadcasting Corporation, such an international frequency comparison will be carried out during the night of March 12-13 next. On this occasion, the output from the frequency standard at the N.P.L. will be employed to modulate waves from the Droitwich, Scottish National and Scottish Regional stations of the B.B.C., simultaneously with the frequency of 1,000 cycles per second, for a period of about an hour and a half. The object of using several stations is to enable observations to be made on two or three carrier frequencies simultaneously, so that the effect of fading phenomena on frequency stability may be studied. On the same night a special emission of a constant frequency of five million cycles per second will be made from the U.S. Bureau of Standards, Washington, of sufficient intensity for satisfactory reception in Europe. Persons and organisations desirous of making use of any of these emissions may obtain further details from Dr. E. H. Rayner, president of Commission I of the U.R.S.I., at the National Physical Laboratory, Teddington, Middlesex.

\section{Protection of Wild Animals in India}

IT is a welcome sign for the welfare of the wild fauna of India that the editor of the Indian Forester (November 1934) should support whole-heartedly F. W. Champion's appeal in the Journal of the Bombay Natural History Society of April. Forestry 